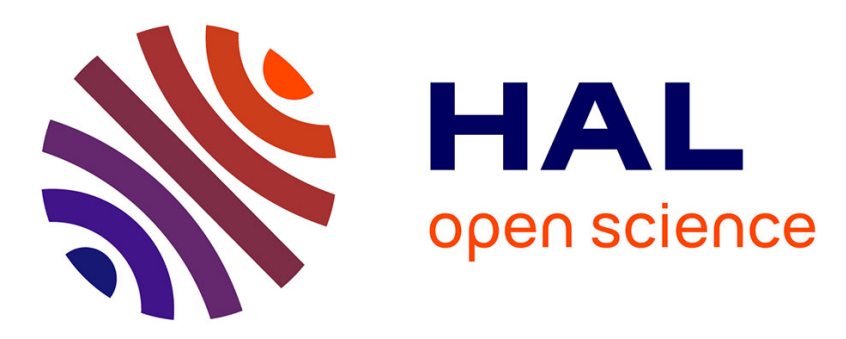

\title{
A methodology to conceive a case based system of industrial diagnosis.
}

Brigitte Chebel-Morello, Mohamed-Karim Haouchine, Noureddine Zerhouni

\section{To cite this version:}

Brigitte Chebel-Morello, Mohamed-Karim Haouchine, Noureddine Zerhouni. A methodology to conceive a case based system of industrial diagnosis.. World Congress of Engineering Asset Management, WCEAM'09., Sep 2009, Athènes, Greece. pp.474-486. hal-00433908

\section{HAL Id: hal-00433908 https://hal.science/hal-00433908}

Submitted on 20 Nov 2009

HAL is a multi-disciplinary open access archive for the deposit and dissemination of scientific research documents, whether they are published or not. The documents may come from teaching and research institutions in France or abroad, or from public or private research centers.
L'archive ouverte pluridisciplinaire HAL, est destinée au dépôt et à la diffusion de documents scientifiques de niveau recherche, publiés ou non, émanant des établissements d'enseignement et de recherche français ou étrangers, des laboratoires publics ou privés. 


\title{
A METHODOLOGY TO CONCEIVE A CASE BASED SYSTEM OF INDUSTRIAL DIAGNOSIS
}

\author{
Brigitte Chebel-Morello ${ }^{\text {a }}$, Karim Haouchine ${ }^{\text {a }}$, and Noureddine Zerhouni1 ${ }^{\text {a }}$ \\ ${ }^{a}$ Automatic Control and Micro-Mechatronic Systems Department FEMTO-ST Institute-UMR CNRS 6174, France, 24 rue \\ Alain Savary, 25000 Besançon - France.
}

\begin{abstract}
The objective of this paper is to address the diagnosis knowledge-oriented system in terms of artificial intelligence, particular by the Case-Based Reasoning (CBR) approach. Indeed, the use of CBR, which is an approach to problem solving and learning, in diagnosis goes back to a long time with the appearance of diagnostic support systems based on CBR. A diagnostic system by CBR implements an expertise-base composed of past experiences through which the origins of failure and the maintenance strategy are given according to a description of a specific situation of diagnostic. A study is made on the different diagnostic systems based on CBR. This study showed that there was no common methodology for building a CBR system. This design depends primarily on the case representation and knowledge models of the domain application. Consequently, this paper proposes a general design approach of a diagnostic system based on the CBR approach.
\end{abstract}

Key Words: Diagnostics, Case-based reasoning, Knowledge management, Functional safety, Hierarchical and contextual models, Adaptation-guided retrieval

\section{INTRODUCTION}

In the field of diagnosis the different studies can be classified in three approaches [7]:

The first one is the analytical approach needing mathematical models, the second one is the data driven approaches like neural networks, systems-based rules, Bayesian networks, neuro-fuzzy networks, etc. And the third one is the knowledge based on causal analysis or expert knowledge.

The choice of the approach depends on the type of available models or information like data or knowledge.

Our choice is directed towards the knowledge-oriented methods and particularly the case based reasoning (CBR). In effect most of the data driven techniques require getting a complete set of learning, while the CBR that allows reasoning on a minimum cases. In effect the reasoning can be done in a few cases, and is less costly for a company than other methods which require a complete learning set to be effective.

\subsection{Domain resources}

[4] thinks the CBR is the technology of choice to implement a knowledge-based system.

Richter [18] defines four knowledge containers involved in a CBR process:

- The vocabulary containers which describing a vocabulary of the domain. This vocabulary is represented by ontology, rules, etc.

- The case base which present a practical solving knowledge coming from experience.

- The similarity containers identifying indexes similarity metrics,

- The adaptation knowledge developing the solution transformation rules, adaptation operators, adaptation cases. 
Knowledge is involved in the CBR cycle. The first "classical" CBR cycle was proposed by Aamodt and Plaza in 1994 [2]. The reasoning is composed into four steps; know as the four" Re": Retrieve, Reuse, Revise and Retain.

The retrieve phase find the most similar case or cases according to the similarity between the request and previously experienced cases stored in the case base. The reuse phase uses solutions of the similar cases in order to solve the new problem. The differences between the reminded case and the new case are taken into account and the old solution is adapted to the new situation. The phase "revise" of the proposed solution evaluates the proposed solution in the real world. And the retain phase store a new case in the case base.

The figure1 presents an evolution of this cycle, by integration of the elaboration step. This step permits to formulate a request problem on a new problem case. In the core of the cycle we can find the four knowledge containers.

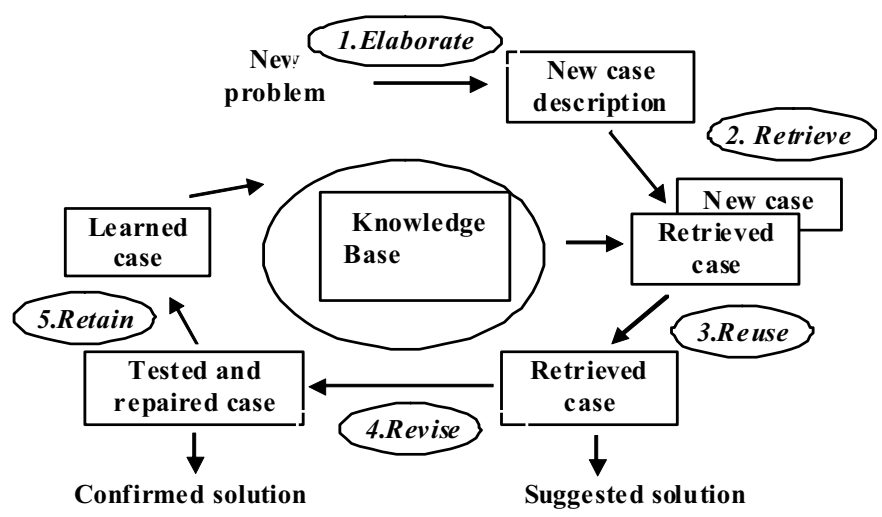

Figure 1. The CBR cycle (Mille, 1999).

However, Cordier in [8] summarise in the table1 the main form that the knowledge containers take and the roles played by the knowledge unit in the different steps of the CBR process.

The containers allow the organisation of the knowledge units but are considered together as a single knowledge base. The typology of CBR knowledge is as follows (see Table 1)

Table 1

Typology of CBR knowledge

\begin{tabular}{|l|l|l|}
\hline Knowledge containers & Knowledge units & Knowledge roles \\
\hline Vocabulary of the domain & Ontology, rules, etc & $\begin{array}{l}\text { Guidance of elaboration } \\
\text { Control of the inference during retrieval } \\
\text { and adaptation }\end{array}$ \\
\hline Case base & $\begin{array}{l}\text { Vectors of attribute value pairs, } \\
\text { structured representations, textual } \\
\text { cases }\end{array}$ & Support in all steps \\
\hline Similarity knowledge & Similarity metrics, indexes & Retrieve a new case \\
\hline Adaptation knowledge & Adaptation rules, operators, cases.... & $\begin{array}{l}\text { Support of the elaboration guidance of } \\
\text { the retrieval realisation of the adaptation }\end{array}$ \\
\hline
\end{tabular}

To present expert knowledge as past and concrete experiences makes its comprehension by human users easy. Lamontagne \& Lapalme [16] represent by two complementary processes a generic model of case based reasoning (see figure 1). A process off line generates the knowledge containers, and a phase of case authoring, and an on line process composed of the different step of the cycle of CBR. 


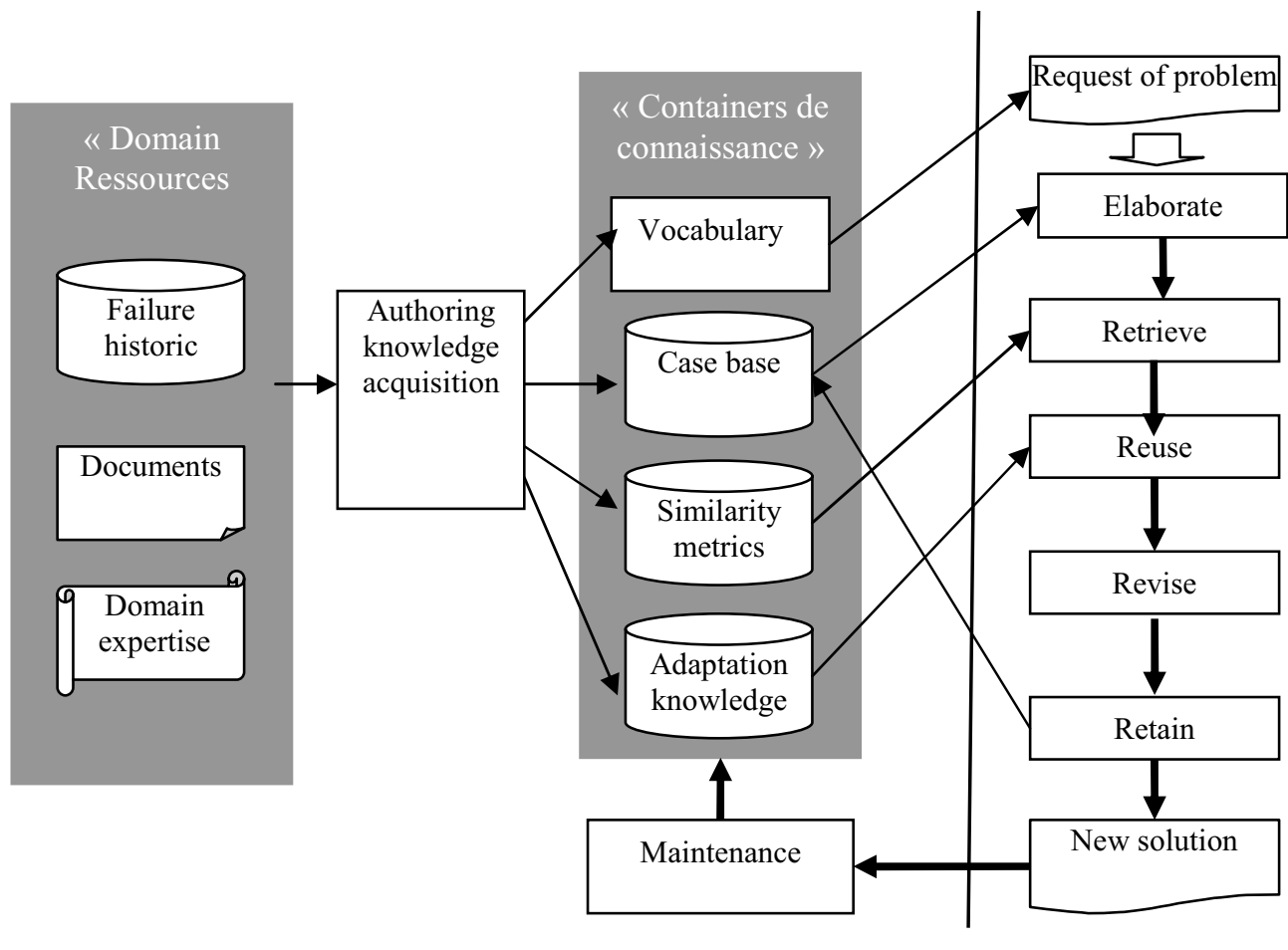

Processus Off-line

Processus On-line

Figure 2. Generic model of a CBR system.

To conceive a system oriented knowledge, we must establish the two processes of this model, the off line process with the different containers knowledge, by authoring case and acquisition knowledge, and the process on line by the different algorithm corresponding at the five step of the CBR process.

\subsection{Case based reasoning on the diagnosis system}

Diagnosis field are recurrent and the previous documented solutions can be used again. In the retrieval of similar cases, algorithms can be used even if problems are not completely understood. The case based reasoning is initially a cycle of four main activities. The retrieval phase determines most similar cases. The reuse phase solves the new problem by using information and knowledge in the retrieved cases. And the revise phase evaluates the applicability of the proposed solution in the real-world. The retain phase updates the case base with the new case for future problem solving.

In [4] two different types of diagnostic systems based on CBR exist:

- In a "help desk" application, CBR is exploited as a decision support, and is used by non-specialists in domains with lots of technical equipment.

- In a "general diagnosis and repair" application, CBR is used as a decision help system for the diagnosis of complex equipment or for medical diagnosis and points out failure cause research and problem exploitation.

The object of the CBR application can vary from a car studied in diagnostic technique system named CREEK [1] to a locomotive defined for remote diagnostics [20] and to a Boeing 747 aircraft developed in CaseLine [21] used as a demonstrator by British Airways and to the Boeing 737 in CASSIOPEE [5] owned by CFM International. There are also an industrial printer studied by Domino UK Ltd in CHEKMATE presented in [12] and gas turbines studied in a fault diagnosis system of General Electric Energy in Atlanta [10].

The current research in case-based reasoning focuses on detailed knowledge representation and adaptation phase. 
Indeed, some systems such as Nodal $_{\mathrm{CBR}}$ [9] and Gas Turbine Diagnostics [10] do not develop an adaptation phase. While others, such as FormTool [6], apply a transformational adaptation but have no knowledge model. Creek system [1] composed of a network of semantic knowledge is handled by three sub tasks namely activation, explanation and focus.

There is a wide variety of method ranging from classification problem when there is just a weak domain theory, to knowledge based systems. In most systems, a case characterizes a diagnostic experience without reference to any kind of model.

The analysis of these different systems pointed out the lack of a proven methodology to register a typical diagnostic case, and methodology of building a case based diagnostic system.

This paper has the objective to propose a methodology to conceive a diagnosis and repair help system based on case based reasoning for human operators.

Three special challenges are solved in this project:

The first one is the proposal of a general representation of the case, based on the diagnosis definition.

The second one is to define knowledge models of the case based reasoning systems. Models adapted to the retrieval and reusing phase of the technical diagnosis.

The third one is to propose three different phase of the on line process the elaboration, retrieval and reusing models.

After presenting a previous works in the elaboration of a methodology of conceives a diagnosis system, we propose a specific formalization of the diagnosis case, based on two descriptor types. Our case formalisation is linked to the dysfunctional mode and to the analysis decomposition of the equipment [17].

After, we propose the different knowledge containers of the system, and we develop a retrieval phase based on the knearest algorithm within two measures (similarity and adaptation measures) depending on the dysfunctional mode and information relevant to the case.

In the last we applied our methodology in industrial equipment namely a diesel motor of the Renault Company.

\section{THE DESIGN APPROACH}

Our design methodology of diagnostic system by CBR takes as a starting point the generic model of Lamontagne and Lapalme [16]. We develop in each process the various containers and steps of CBR cycle.

\subsection{Previous works and methodology following}

Among the work on the diagnosis, the systems are describing without defining the methodology for obtaining the components of the system.

We are interested in previous work on this issue. We are proposed a mix method of knowledge capitalization and case based reasoning in order to develop a diagnosis system. The knowledge capitalization cycle was adopted as the underlying principle Rasovska et al [17]. This method integrates a representation and a reasoning model both completing each other and suitable to represent and manipulate the domain knowledge.

Our system, like Creek for example, is based on the operating safety tools [17] and proposes functional, dysfunctional or causality models. These models can be aggregated in a network of semantic knowledge as a Creek or be proposed in the case of our study, in the form of two models: hierarchical and contextual.

\subsection{Off-line process}

For the diagnostic system design we first define the off-line process (see Figure 2).

\section{Documents}

We propose to use the documents produced for a given maintenance process (alarm handling, diagnosis, etc.) as our basic building blocks for the case model. And, because all this information may be retrieved from a given intervention report, we 
choose the intervention reports database as our case base model. These two models will be completed and improved by the experience feedback

\section{Authoring}

In [17] we were interested in case formalisation with the proposal of ontology. In this paper we go further and we define the case as a set of descriptors based on the diagnostic reference definition: "these are the actions carried out for the fault detection, its localization and the identification of the cause" [3]. Consequently, the diagnostic is composed of three parts: the fault detection part, the part concerning the zone localization in which the failure occurred and the identification part of the failing component. We develop these three phases in the case design; moreover, will base on the equipment knowledge models to be diagnosed. We summarize the three parts as follows:

Detection: we determine on the equipment the failure class based on the FMEA (Failure Mode and Effects Analysis). This class belongs to the solution of our case.

Localization: this part is described in the first problem part of the case. It allows determining thanks to a context model the equipment failure zone.

Identification: this identification concerns on the one hand, the second part of the case problem which one names "functional part" and on the other hand, the solution part while allowing to identify the failing component. The functional part is based on a components hierarchal model in which the classes of this model are found in the functional descriptors in order to obtain a generic case.

We represent the industrial diagnostic problem in the most general possible way.

A case has object formalization and allows defining a hierarchy of descriptors containing as well the problems descriptors as the solution descriptors.

The descriptors are represented by three attributes. We associate to each attribute the modal values forming a partition contiguous to the considered attribute. One of specificities of our study case is to determine a state and a operating mode, with each component to be diagnosed [13]. Therefore, we assign to a given descriptor:

- An attribute on its value itself (the descriptor is an electrical or mechanical component for example);

- An attribute on the its status;

- And an attribute relating to the operating mode which will reflect the normal and/or abnormal state of the equipment components.

The problem descriptors of the functional part will have consequently three attributes relating to the value of the component, its state and its operating mode: $\mathrm{ds}_{\mathrm{i}}=\left(d_{s i}^{\text {value }}, d_{s i}^{\text {state }}, d_{s i}^{F M}\right)$.

By taking account of all these specificities, we can schematize the case structure as shown in the Figure 3.

\begin{tabular}{|c|c|c|c|c|c|c|c|c|c|c|}
\hline \multicolumn{8}{|c|}{ Problem part } & \multicolumn{3}{|c|}{ Solution part } \\
\hline Localization & & & & ctio & & & & Class & $\begin{array}{c}\text { Failure } \\
\text { component }\end{array}$ & \\
\hline $\mathrm{ds}_{1} \ldots \mathrm{ds}_{1}$ & $d s_{l+1}^{\text {value }}$ & $d s_{l+1}^{\text {state }}$ & $d s_{l+1}^{F . M}$ & $\cdots$ & $d s_{m}^{\text {value }}$ & $d s_{m}^{\text {state }}$ & $d s_{m}^{M . F}$ & $\mathrm{Ds}_{1}$ & $\mathrm{Ds}_{2}$ & .. \\
\hline
\end{tabular}

Figure 3. Structure générique du cas de diagnostic.

We identify the relevant descriptors for the case representation according to the studied field and a suitable structure of the associated cases with the general knowledge models. This identification allows the installation of the two retrieval and adaptation phases and the exploitation of the comparison between these two phases through the creation of the appropriate measures.

\section{The knowledge containers}

The case-base container contains all the previously definite cases. Thereafter, we will develop the three remaining containers. 


\section{The vocabulary container}

The vocabulary container contains the knowledge models of the CBR system.

The representation of knowledge of our CBR system dedicated to diagnostic is shown on Figure 1.

It consists of two models supplementing the dysfunctional part of our system which is the case-base, and by decision rules determining the component operating mode within the operating context of this one.

The equipment model is resulting from a equipment decomposition of the studied system which determines the functions performed by the equipment and its components. The components taxonomy model is determined from their functional analysis. Each components set is gathered by functional class.

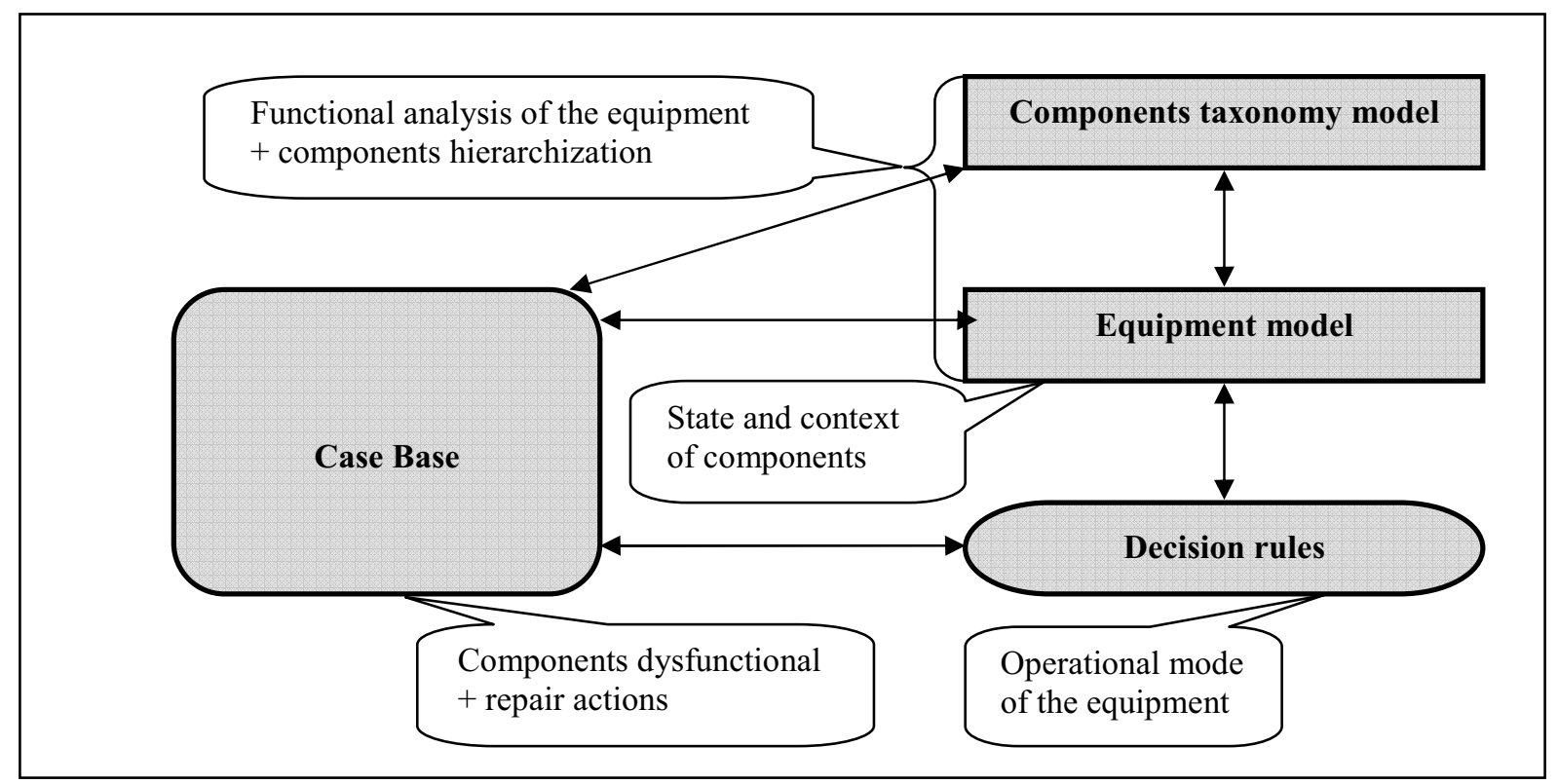

Figure 4. Représentation des connaissances d'un système de RàPC dédié au diagnostic de pannes.

The knowledge representation is based on two models namely the context model and the components taxonomy model. The context model is based on flows of specific magnitudes of the system and on the equipment decomposition analysis of the studied system. This decomposition determines the functions provided by the equipment and its components. As for the components taxonomy, it determines the equipment sets starting from their functional analysis. Each components set is grouped according to the operating similarity or ensured by the same functions. We associate with these two models and the case-base another module concerning the decision rules for determining the system operating mode to be diagnosed.

\section{The similarity measures container}

Before the Nineties, the two retrieval and adaptation phases were exploited in a completely independent way. Until Smyth and Keane [19] bring a new breathe and suggest the unification of these two phases. This unification goes in the direction where the chosen case in the retrieval phase is that most easily adaptable in order to optimize the adaptation phase results. Our recent work goes in this direction and we have proposed in [13] two measures, one of similarity and one of adaptation.

In our study, the retrieval phase is based on the $\mathrm{k}$ nearest neighbours algorithm, on the components taxonomy and on the measures being in the similarity measures container. In order to select, among the retrieved cases, the most favourable case to the adaptation, we must initially evaluate the similarity of the source cases to the case to solve by applying a global similarity measure which is composed by a set of local similarity measures. Then, we will take account of the descriptors operating mode of the functional part via a $\lambda \mathrm{i}$ weight in the second measure that called: Adaptation Measure $\left(\mathrm{A}_{\mathrm{M}}\right)$.

\section{- Retrieval Measure}

We initiated the Retrieval Measure $\left(\mathrm{R}_{\mathrm{M}}\right)$ in [13]. We recall that this measure is composed of four local similarities: 
For the value of $d_{s i}^{\text {value }}$, which belongs to the hierarchical model of descriptors, $\varphi^{\text {value }}$ is developed.

If $d_{s i}^{\text {value }}=d_{t i}^{\text {value }}$ then $\varphi^{\text {value }}=1$, And

if $d_{s i}^{\text {value }} \neq d_{\text {ti }}^{\text {value }}$ then $\varphi^{\text {value }}=0.8, \varphi^{\text {value }}=0.6 \ldots$ or $\varphi^{\text {value }}=0$

For the descriptor value $d_{s i}^{\text {state }}, \varphi^{\text {state }}$ is developed

If $d_{s i}^{\text {state }}=d_{t i}^{\text {state }}$ then $\varphi^{\text {state }}=1$, and if $d_{s i}^{\text {state }} \neq d_{t i}^{\text {state }}$ then $\varphi^{\text {state }}=0$

For the functional mode defined in $d_{s i}^{F M}, \varphi^{F M}$ id developed

If $d_{s i}^{F M}=d_{t i}^{F M}$ then $\varphi^{F M}=1$, and if $d_{s i}^{F M} \neq d_{t i}^{F M}$ then $\varphi^{F M}=0$

To take into account the information in descriptors, a local similarity $\varphi^{\text {presence }}$ is developed. $\varphi^{\text {presence }}=1$, when the descriptor is indicated in the source case and $\varphi^{\text {presence }}=0$, if not.

The global similarity measure (1) is obtained by aggregation of these functions on the whole set of descriptors. From this measure, a set of cases can be selected.

$$
R_{M}=\frac{\sum_{i=1}^{m} \varphi_{i}^{\text {Valeur }} \times \varphi_{i}^{\text {Etat }} \times \varphi_{i}^{\text {Pr ésence }} \times \varphi_{i}^{M . F}}{\sum_{i=1}^{m} \varphi_{i}^{\text {Présence }}}
$$

Where n: represent the number of problem descriptors.

Thus, this measure will provide a set of the most similar cases to the case to solve. In order to select the most adaptable retrieved case, we have introduced a measure called: Adaptation Measure $\left(\mathrm{A}_{\mathrm{M}}\right)$.

\section{- $\quad$ Adaptation Measure}

The Adaptation Measure $\left(\mathrm{A}_{\mathrm{M}}\right)$ takes account of the components operating mode by attaching importance to the abnormal operating mode in the case source descriptors (dsi) and the case target descriptors (dti), by providing them with greater weight. This importance will be characterized by the $\lambda i$ weight.

The adaptation measure $\left(A_{M}\right)(2)$ takes into account the source cases descriptors which are different from case target and will be linked to the class and to the functional mode compared to the solution descriptors.

$$
A_{M}=\frac{\sum_{i=1}^{n} \varphi_{i}^{\text {Class }} \cdot \lambda_{i}}{\sum_{i=1}^{n}\left(\varphi_{i}^{F . M}+\varphi_{i}^{\text {state }}\right) \cdot \varphi_{i}^{\text {value }}}
$$

Where $\lambda \mathrm{i}$ is the associated weight according to the functional mode

If $\mathrm{FM}=$ normal $\rightarrow \lambda \mathrm{i}=2^{0}$; if $\mathrm{FM}=$ abnormal $\rightarrow \lambda \mathrm{i}=2^{2}$; if $\mathrm{FM}=$ nor $/ \mathrm{ab} \rightarrow \lambda \mathrm{i}=2^{1}$.

A weight is associated to the functional mode because this last is considered as being important in the determination of the failing component. The number of different descriptors is determined by the denominator in the equation (2). The retrieved 
source case having the greatest adaptation measure value among the retrieval source cases will be the candidate chosen for the adaptation step.

\section{The adaptation container}

We set up in an adaptation algorithm the dependency relations between the various problem and solution descriptors. These relations allow to express the influence of a problem descriptor "ds" on the solution descriptors "Ds" in the various sources cases of the case-base. These relations will help to define relevant descriptors set which could be used in the adaptation phase. Their implementation is explained in [13]. Three values are assigned to the various cases source descriptors according to the link between problem and solution spaces, $\mathrm{DR}=\{$ high, low, none $\}$.

The method has been validated in our works of [13].

\subsection{On-line process}

The on-line process contains various cycle phases. We develop three phases namely: elaboration of the target case, retrieval and adaptation.

\section{Elaboration phase}

At the time of failure, the user requests the diagnostic help system which proceeds in three steps: a failure localization step which is done thanks to the equipment model. This model provides a certain components set that could potentially failing by their geographical proximity of the concerned zone. Thus, the elaboration phase will be initialized by the filling of the associated descriptors with the "failure localization". By a consultation of the supervisor SCADA (Supervisory Control And Data Acquisition) step, giving us the actual state of the various components. Then, by a decision phase, which is starting from the actual position of these components, implements decisions rules giving the operating mode of the implied components. This allows the part of the problem descriptors of the target case to knowing its localization part and its operating mode part (normal/abnormal) to be informed (Figure 5). It is to be noted that the cause and effect relation is taken into account during the case-base creation. The various components are linked by their state, which results in the case-base descriptors values and therefore the definition of their operating mode. Indeed, a component can be in an abnormal operating mode state but it is not failing. This can happen because of the influence of another failing component.

Identification

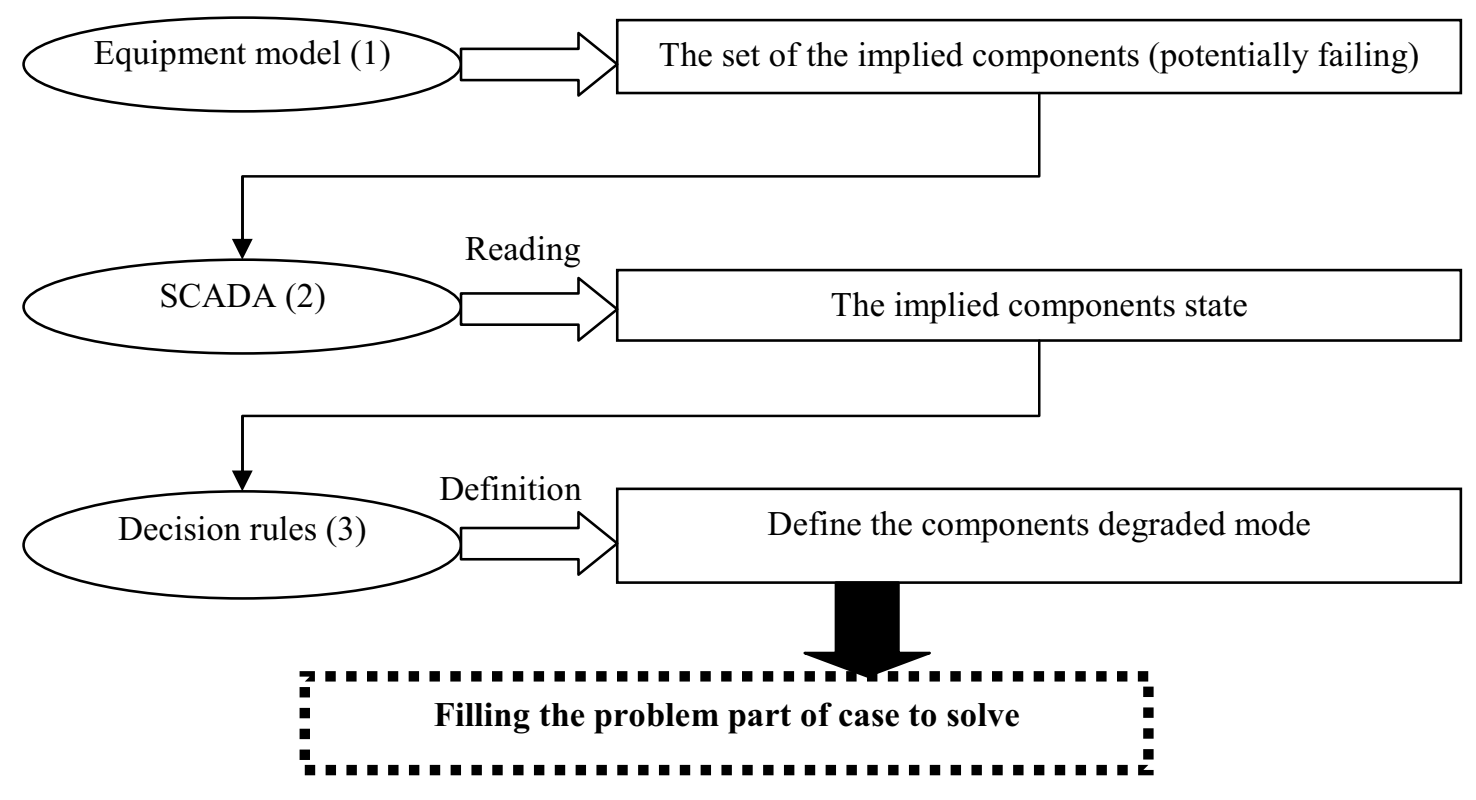

Figure 5. Les différentes étapes d'élaboration du cas cible. 


\section{Adaptation guided retrieval}

The retrieval phase is based on the two installation measures $\left(A_{M}\right)$ and $\left(R_{M}\right)$ in order to guide the adaptation. Indeed, a first retrieval phase allows thanks to the k nearest neighbours algorithm to define a set of most similar cases to the case to be solved. The $\left(\mathrm{A}_{\mathrm{M}}\right)$ measure is used to select among all retrieved cases the most easily adaptable case.

\section{Adaptation}

The adaptation phase is carried out thanks to an algorithm relies on the context model, the descriptors hierarchical model and the dependency relations. The dependency relations are inspired by Fuchs' work in [11].

The adaptation algorithm is presented in [14]. This algorithm adapts descriptor by descriptor. Three standard adaptation cases have been identified, namely:

- DR high involving at least a solution descriptor with a problem descriptor belonging to the same operating class;

- DR high involving at least a solution descriptor with a problem descriptor belonging to different operating classes;

- DR low.

The adaptation guided retrieval was validated on supervised industrial system of pallets transfer (SISTRE) [15]. Thus, we have proved the feasibility of our diagnostic help system. This allowed to set up an design approach of diagnostic help system applied to another industrial equipment, in this case a diesel motor $1.5 \mathrm{dCi} \mathrm{K} 9 \mathrm{~K} 105 \mathrm{ch}$ of Renault company available to the following link: http://v3.renault.com/cfm/module-K9K/fr/index.html.

\section{APPLICATION}

A functional and dysfunctional study of a motor diesel was introduced for the construction of case-base and knowledge models of the diagnostic help system. We develop in what follows the installation of the used documents, the case base and the knowledge models.

\subsection{Les documents}

The used documents result from the diesel motor technical documentation which is available at: http://v3.renault.com/cfm/module-K9K/fr/index.html. This documentation enabled to determine various existing flows in the motor and its components. Moreover, we called upon an expert, in particular a mechanic, who helped us to define the components operating modes and to analyze the causal relations.

\subsection{The motor case-base}

Through the functional and dysfunctional study of the motor, we built a case-base containing 130 cases. The case problem part is composed of 12 descriptors. The first four descriptors determine the failure zone field of motor equipment. This zone is determined by "ds1: the motor state", "ds2: the glow plugs state", "ds3: temperature of the motor" and "ds4: failure sub zone".

Figure 6 shows an overview of the parts problem and solutions of seven cases of the diesel motor case-base. 


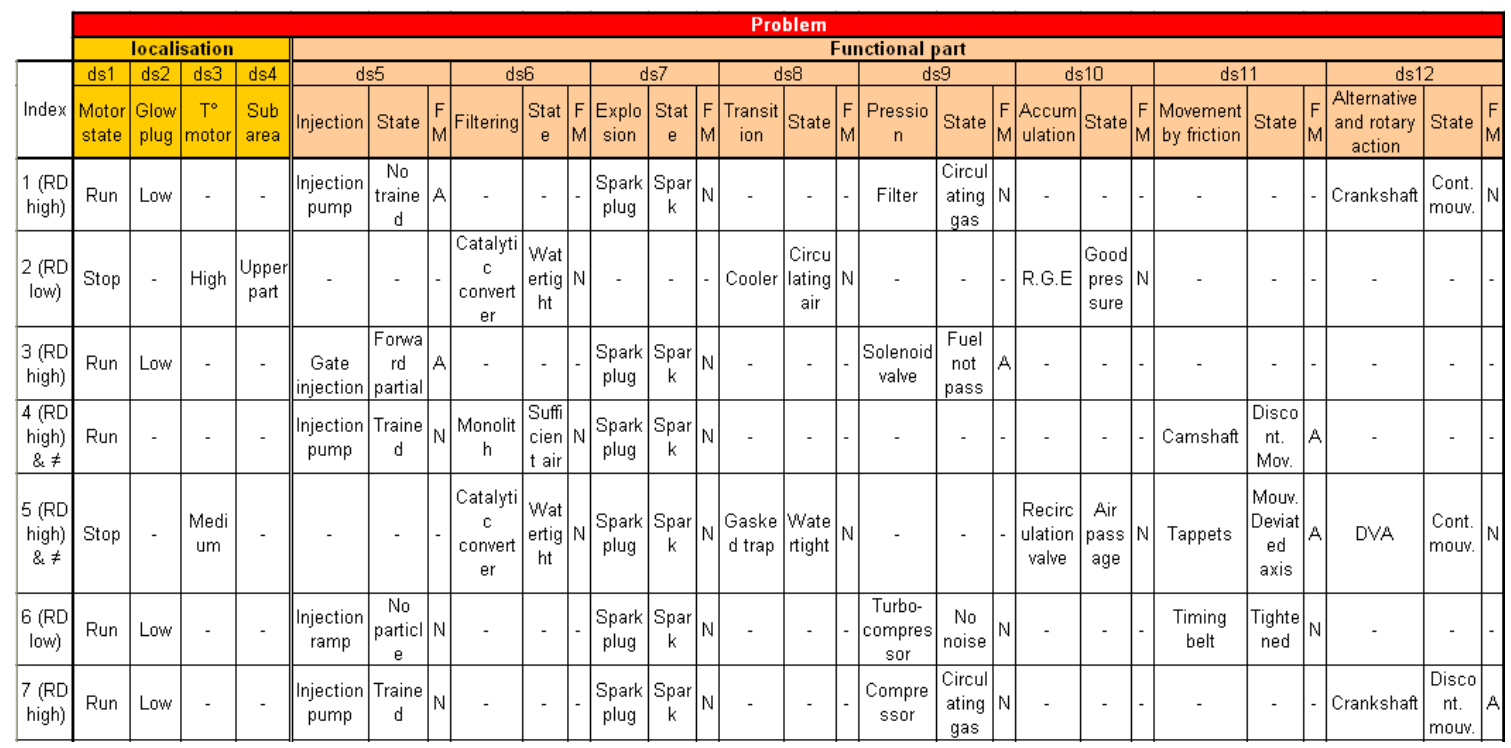

\begin{tabular}{|c|c|c|c|}
\hline \multicolumn{4}{|c|}{ Solution } \\
\hline $\begin{array}{c}\text { Failure } \\
\text { classe }\end{array}$ & $\begin{array}{c}\text { Identification } \\
\text { failure } \\
\text { componant }\end{array}$ & $\begin{array}{c}\text { Associated } \\
\text { repair action }\end{array}$ & Failure area \\
\hline $\begin{array}{c}\text { Coupling } \\
\text { mobile }\end{array}$ & Injection pump & $\begin{array}{c}\text { Changing } \\
\text { pump }\end{array}$ & Fuel \\
\hline $\begin{array}{c}\text { Coupling } \\
\text { mobile }\end{array}$ & $\begin{array}{c}\text { Turbo- } \\
\text { compressor }\end{array}$ & $\begin{array}{c}\text { Changing } \\
\text { filter }\end{array}$ & Exhaust \\
\hline $\begin{array}{c}\text { Coupling } \\
\text { mobile }\end{array}$ & Solenoid valve & $\begin{array}{c}\text { Replacing } \\
\text { files } \\
\text { valvenoid }\end{array}$ & Fuel \\
\hline $\begin{array}{c}\text { Movement } \\
\text { by pressure }\end{array}$ & Pistons & $\begin{array}{c}\text { Changing } \\
\text { pistons }\end{array}$ & Fuel + \\
\hline $\begin{array}{c}\text { Movement } \\
\text { by pressure }\end{array}$ & Pistons pins & $\begin{array}{c}\text { Replacing } \\
\text { pistons pins }\end{array}$ & Fxhaust \\
\hline $\begin{array}{c}\text { Rotary } \\
\text { action }\end{array}$ & $\begin{array}{c}\text { Pinion of } \\
\text { crankshaft }\end{array}$ & $\begin{array}{c}\text { Replacing } \\
\text { pignon of } \\
\text { crankshaft }\end{array}$ & Fxhaust \\
\hline $\begin{array}{c}\text { Rotary } \\
\text { action }\end{array}$ & Crankshaft & $\begin{array}{c}\text { Lubrication } \\
\text { of crankshaft }\end{array}$ & Fuel \\
\hline
\end{tabular}

Figure 6. A part of the case-base of Renault gas motor.

Let us take the example of case 1. This last reflects a failure on the injection pump. The problem part determines in its "localization" part the failing component place which is defined by the context model. According to the first four descriptors, the motor is running, the glow plugs are in a bad condition and the two remaining descriptors are not indicated. When referring to the context model, we find a number of components which are potentially failing in the specified zone. Then, the case functional part indicates the components state in this zone. The "ds5" descriptor which reflects the "pump injection" component belonging to the "injection" class is in a "no trained" state generating an "abnormal" operating mode. The "ds7" descriptor reflects the candle state which is in a "normal" operating mode because it produces sparks. The "ds9" descriptor describes the filter component that normally circulates gas. The "ds 12 " descriptor indicates that the crankshaft has a continuous motion and is in "normal" operating mode. The other descriptors are not indicated.

As for the solution part, the "Ds1" descriptor indicates that the concerned component failure class is "coupling mobile". "Ds2" specifies that the failing component is the "injection pump" with a remark that this pump does not deliver fuel. Thus, the associated repair action which is described by "Ds3" descriptor recommends a change of the injection pump. Finally, the "Ds4" descriptor indicates that the failure occurred on the fuel passage flow. 


\subsection{The knowledge models}

The knowledge representation is based on two models associated with the case-base, namely: the context model and the components taxonomy model.

The equipment analysis determines sets of these components. Each set includes components which provide the same functions. This functional analysis allows having a hierarchical modelling of the equipment. Figure 1 shows an example of the components hierarchical model of a diesel motor.

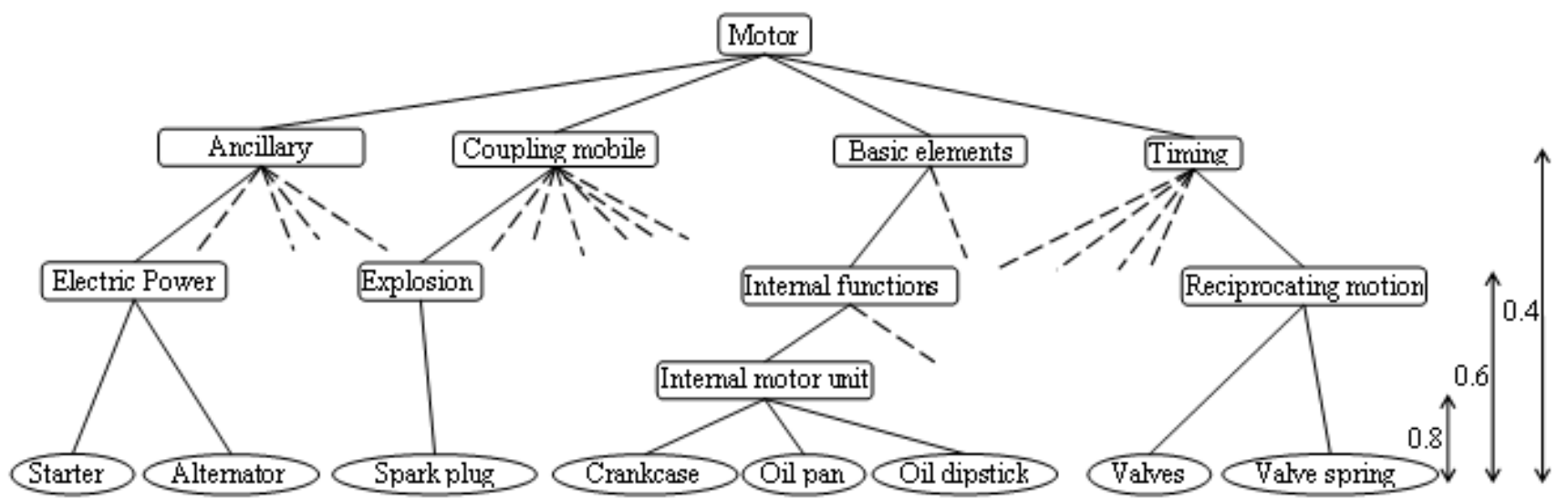

Figure 7. Aperçu du modèle hiérarchique des composants moteur.

As the motor has a multiplicity of components, we show that part of the components hierarchical model. This model includes four classes: Ancillary, Coupling mobile, Basic elements and Timing. Each class is composed of subclasses until we arrive at the level of components.

The context model is based on flows of the system entities and on the equipment decomposition analysis of the studied system. This decomposition determines the functions provided by the equipment and its components. These components constitute the context in which the failing component is identified.

The context reflects the cause-and-effect relations permitting to locate components with problems and to select the good descriptors compared to the set. Figure 2 shows an overview of the diesel motor context model.

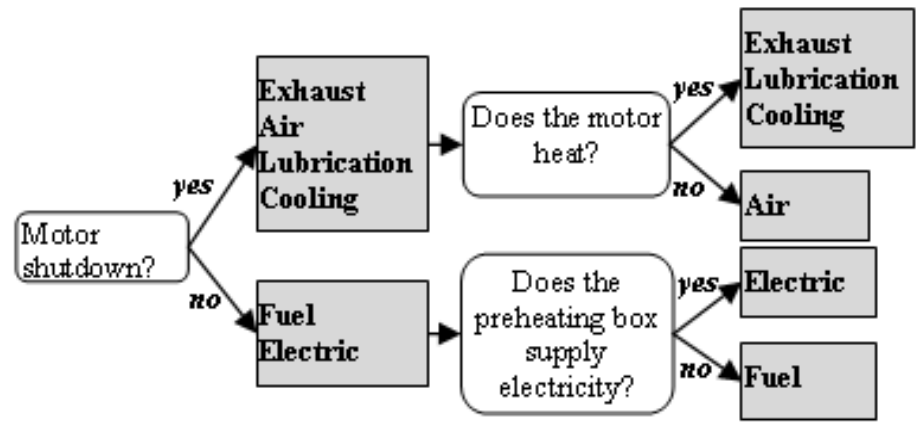

\begin{tabular}{|l|}
\hline Context of Ds \\
\hline "Fuel area" \\
\hline \\
$D s_{1}$ : Injection pump does not deliver oil IP=f(GI, IR, F, SP) \\
$D s_{1}$ : Gate injection is stopped $\mathrm{GI}=\mathrm{f}(\mathrm{IP}, \mathrm{IR}, \mathrm{F}, \mathrm{SP})$ \\
$\mathrm{D} s_{1}$ : Injection ramp is blocked IR=f(IP, GI, F, SP) \\
$\mathrm{Ds}$ : Filter leaking $\mathrm{F}=\mathrm{f}(\mathrm{IP}, \mathrm{GI}, \mathrm{IR}, \mathrm{SP})$ \\
$\mathrm{D} s_{1}$ : spark plug is no gleam $\mathrm{SP}=\mathrm{f}(\mathrm{IP}, \mathrm{GI}, \mathrm{IR}, \mathrm{F})$ \\
\hline
\end{tabular}

Figure 8. Aperçu du modèle de contexte d'"un moteur à explosion.

The context model is set up according to different natures of flow in the motor. The flows which we identified are: exhaust, air, lubrification, cooling, fuel and electric. Each flow implies a number of components. Each class can contain several flows and also each flow can contain several classes.

The retrieval phase will take account of three attributes types of the case functional part. The adaptation phase will exploit the dependency relations by traversing a context model which defines the cause and effect relations between descriptors.

To evaluate our method of adaptation guided retrieval and the adaptation algorithm, we set up a specific protocol. This protocol relates to the division of the diesel motor case-base in two subsets. The first subset contains $40 \%$ of cases drawn randomly from the case-base forming the training set. The $60 \%$ of the remaining cases will constitute the test set. The goal of this protocol is to calculate the training case-base accuracy. We indicate that the accuracy relates to the determination of the good failure class. 
We found that our retrieval and adaptation method ensured a very high accuracy. In fact, we can conclude that CBR can reason from a limited number of cases, based on knowledge models and on adaptation phase adjusted to the considered application. Moreover, the retrieval phase, which uses two retrieval and adaptation measures, takes account of the adaptation effort and selects the most easily adaptable cases and amongst other things the cases which have the same classes.

\section{CONCLUSION}

Within the study framework made on the industrial diagnostic help and repair systems, we proposed a system of diagnostic based on the case-based reasoning approach (CBR) with the deployment of the different phases. The designed system includes an object formalization of case associated with a hierarchical model common to the problem and solution descriptors of the case-base cases and a model in relation to the application context. All CBR phases depend on the cases formalization associated with the knowledge models. Recently in [13], we formalized a case for SISTRE equipment. This formalization is adapted to our method. The selected modelling influences proposed retrieval and adaptation measures. This latter is directly related to the operating mode of the monitored components (a specific attribute of a descriptor). The developed retrieval phase is guided by the adaptation in exploiting the relations of the two installation measures namely: Retrieval Measure $\left(\mathrm{R}_{\mathrm{M}}\right)$ and Adaptation Measure $\left(A_{M}\right)$. These relations enable to select among the retrieved cases those which are most easily adaptable. The adaptation phase operates the dependency relations between the problem and solution descriptors. These dependency relations are determined through relevant descriptors or using the context model reflecting the cause and effect relations between the equipment components. We have detected three standard cases, in the adaptation algorithm, associated with the different values of the dependency relations.

In order to prove the feasibility of our approach, we have established in this paper our CBR diagnostic system on a diesel motor $1.5 \mathrm{dCi}$ K9K $105 \mathrm{ch}$ of the "Renault" company.

We plan in a near future to apply a maintenance method of the installation CBR system. Indeed, the system's evolution through time is done by the introduction of new cases following the appearance of new failures. This evolution may deteriorate the case-base quality and that two retrieval and adaptation measures can become obsolete. This maintenance method would allow the evolution of these two measures (as example while inserting weights) and of the case-base according to the system evolution.

\section{REFERENCES}

1 Aamodt A. (2004) Knowledge-Intensive Case-Based Reasoning and Sustained Learning, Proc. of the $9^{\text {th }}$ European Conference on Artificial Intelligence, ECCBR'04, pp.1-15.

2 Aamodt A \& Plaza E. (1994) Case-Based Reasoning: Foundational Issues, Methodological Variations, and System Approaches. AI Communications, 7(i): pp 3959.

3 Afnor (2001). Maintenance terminology. European standard, NF EN 13306.

4 Althoff K.D. (2001) Case-Based Reasoning. S.K. Chang (Ed.), Handbook on Software Engineering and Knowledge Management, pp. 549-588.

5 Bergmann R, Althoff KD, Breen S, Göker M, Manago M, Traphöner R \& Weiss S. (2003) Developing Industrial CaseBased Reasoning Applications: The INRECA Methodology. Lecture Notes in Artificial Intelligence, LNAI 1612 , Springer Verlag, Berlin.

6 Cheetham W \& Graf J. (1997) Case-Based Reasoning in Color Matching., the $2^{\text {nd }}$ Second International Conference on CBR Research and Development, pp.1-12, vol. 1266.

7 Chiang, L, Russell E \& R Braatz (2001). Fault Detection and Diagnosis in Industrial Systems. London Great Brintain: Springer.

8 Cordier A. (2008) Interactive and Opportunistic Knowledge Acquisition in Case-Based Reasoning. Thesis, Laboratoire d'InfoRmatique en Images et Systèmes d'information, Université de Lyon I.

9 Cunningham P \& Smyth B. (1994) A Comparison of Model-Based and Incremental Case-Based Approaches to Electronic Fault Diagnosis, AAAI, Seattle, USA.

10 Devaney M \& Cheetham B. (2005) Case-Based Reasoning for Gas Turbine Diagnostics, In $18^{\text {th }}$ International FLAIRS Conference (FLAIRS-05).

11 Fuchs, B., Lieber, J., Mille, A., Napoli, A.: An Algorithm for Adaptation in Case-Based Reasoning. In Proceedings of the 14th ECAI, Berlin, Germany, p. 45-49, (2000). 
12 Grant PW, Harris PM \& Moseley LG. (1996) Fault Diagnosis for Industrial Printers Using Case-Based Reasoning. Engineering Applications of Artificial Intelligence. Vol.9, No.2, pp.163-173.

13 Haouchine MK, Chebel-Morello B \& Zerhouni N. (2008a) Adaptation-Guided Retrieval for a Diagnostic and Repair Help System Dedicated to a Pallets Transfer. In 3rd European Workshop on Case-Based Reasoning and ContextAwareness. 9th European Conference on Case-Based Reasoning, ECCBR 2008, Trier, Germany.

14 Haouchine MK, Chebel-Morello B \& Zerhouni N. (2008b) Conception d'un Système de Diagnostic Industriel par aisonnement à Partir de Cas. Actes du 16ème Atelier de Raisonnement à Partir de Cas, RàPC'2008, Nancy, France.

15 Haouchine MK, Chebel-Morello B \& Zerhouni N. (2009) Algorithme d'Adaptation pour le Diagnostic Technique. Actes du $17^{\text {ème }}$ Atelier de Raisonnement à Partir de Cas, RàPC'2009, Paris, France.

16 Lamontagne L \& Lapalme G. (2002) Raisonnement à base de cas textuels - état de l'art et perspectives, Revue d'Intelligence Artificielle, Hermes, Paris, vol. 16, no. 3, pp. 339-366.

17 Rasovska I, Chebel-Morello B \& Zerhouni N. (2007) A Case Elaboration Methodology for a Diagnostic and Repair Help. FLAIRS-20 Key West, Florida, May 7-9.

18 Richter M.M., The Knowledge Contained in Similarity Measures. Invited talk, First International Conference on CaseBased Reasoning (ICCBR'95), Sesimbra, Portugal, 1995.

19 Smyth B \& Keane MT. (1993) Retrieving Adaptable Cases. The role of adaptation knowledge in case retrieval, in proceedings of EWCBR'93, LNAI 837, éd. Springer.

20 Varma A \& Roddy N. (1999) ICARUS: A case_Based System for Locomotive Diagnostics. Applications of Artificial Intelligence Journal.

21 Watson I \& Marir F. (1994) Case-Based Reasoning : A Review, The Knowledge Engineering Review, 1994. 